\title{
Nitrogen modification of hydrogenated amorphous carbon films
}

\author{
S. R. P. Silva ${ }^{\mathrm{a})}$ \\ Department of Electronic and Electrical Engineering, University of Surrey, Guildford, Surrey GU2 5XH, \\ United Kingdom \\ J. Robertson \\ Cambridge University, Engineering Department, Trumpington Street, Cambridge CB2 1PZ, \\ United Kingdom \\ G. A. J. Amaratunga \\ Department of Electrical Engineering, University of Liverpool, Brownlow Hill, Liverpool L69 3BX, \\ United Kingdom \\ B. Rafferty and L. M. Brown \\ Physics Department, Cambridge University, Madingley Road, Cambridge CB3 OHE, United Kingdom \\ J. Schwan \\ University of Kaiserslautern, Department of Physics, Kaiserslautern 67663, Germany \\ D. F. Franceschini \\ Departamento de Fisica, Pontificia Universidade Catolica do Rio de Janeiro, Cx 38071, 22452-970, \\ Rio de Janeiro, Brazil \\ G. Mariotto \\ Universita degli Studi di Trento, Department of Physics, 1-38050 Povo, Trento, Italy
}

(Received 26 July 1996; accepted for publication 20 November 1996)

The effect of nitrogen addition on the structural and electronic properties of hydrogenated amorphous carbon $(\mathrm{a}-\mathrm{C}: \mathrm{H})$ films has been characterized in terms of its composition, $\mathrm{sp}^{3}$ bonding fraction, infrared and Raman spectra, optical band gap, conductivity, and paramagnetic defect. The variation of conductivity with nitrogen content suggests that $\mathrm{N}$ acts as a weak donor, with the conductivity first decreasing and then increasing as the Fermi level moves up in the band gap. Compensated behavior is found at about 7 at. $\% \mathrm{~N}$, for the deposition conditions used here, where a number of properties show extreme behavior. The paramagnetic defect density and the Urbach tailwidth are each found to decrease with increasing $\mathrm{N}$ content. It is unusual to find alloy additions decreasing disorder in this manner. (C) 1997 American Institute of Physics.

[S0021-8979(97)02605-4]

\section{INTRODUCTION}

Recent studies of nitrogen additions to amorphous carbon (a-C) have been motivated by two factors; the synthesis of the possible superhard compound $\mathrm{C}_{3} \mathrm{~N}_{4},{ }^{1}$ and the electronic doping of a-C. We are interested here in the semiconducting forms of $\mathrm{a}-\mathrm{C}$ and hydrogenated $\mathrm{a}-\mathrm{C}(\mathrm{a}-\mathrm{C}: \mathrm{H})$ which can be doped electronically using nitrogen. Meyerson and Smith $^{2}$ observed that a-C:H could be doped $n$ - and $p$-type by phosphorus and boron, respectively, in a similar fashion to $\mathrm{a}-\mathrm{Si}: \mathrm{H}$. They concluded that there was true substitutional doping by observing the thermopower sign reversal expected as the conductivity changed from $n$ - type to $p$-type. ${ }^{3}$ However, the doping effect was weaker than in a-Si:H. Indeed, Jones and Stewart ${ }^{4}$ found still lower doping efficiencies and they questioned whether true doping was occurring. Interestingly, they observed that nitrogen was able to increase the conductivity of a-C:H, and this has since been repeated by numerous other groups. ${ }^{4-10}$ However, it has been unclear whether $\mathrm{N}$ increased the conductivity by doping-raising the Fermi level towards the conduction band, or by graphitization of the bonding-narrowing the band gap. ${ }^{7}$

${ }^{a)}$ Electronic mail: s.silva@ee.surrey.ac.uk
Recently, a highly $\mathrm{sp}^{3}$ bonded form of a-C denoted tetrahedral amorphous carbon (ta-C) has been deposited by filtered cathodic vacuum arc (FCVA). ${ }^{11} \mathrm{Ta}-\mathrm{C}$ is a semiconductor with a $2.5 \mathrm{eV}$ wide band gap. Undoped ta-C is moderately $p$-type. ${ }^{12}$ Ta-C can be doped in a rather uncontrollable fashion by $\mathrm{P} .{ }^{13}$ It can be doped more controllably by $\mathrm{N},{ }^{14,15}$ and $\mathrm{N}$ was found to first decrease the conductivity, then increase it, as $E_{F}$ moves upwards in the band gap, from near the valence band, through midgap, to close to the conduction band edge $E_{C}$. The optical gap and the fraction of $\mathrm{sp}^{3}$ bonding were both found to remain constant during these $\mathrm{N}$ additions, and they only decreased at higher $\mathrm{N}$ contents. It was clear that $\mathrm{N}$ acted as a substitutional donor in ta-C, although with low doping efficiency.

Subsequently, a hydrogenated analogue of ta- $\mathrm{C}$, ta-C:H, was prepared by deposition from a low pressure plasma beam source. ${ }^{16} \mathrm{Ta}-\mathrm{C}: \mathrm{H}$ has an optical gap of $2.7 \mathrm{eV}$, but again the conductivity activation energy for undoped ta-C:H is much less than half the optical gap, suggesting that $E_{F}$ lies well away from midgap. $\mathrm{N}$ additions to ta- $\mathrm{C}: \mathrm{H}$ are also found to give a strong increase in the conductivity, while the optical gap remains unchanged. ${ }^{17}$ In this case, it was not possible to observe the initial decrease in conductivity as $E_{F}$ passed through midgap. These latter results, therefore, suggest that 


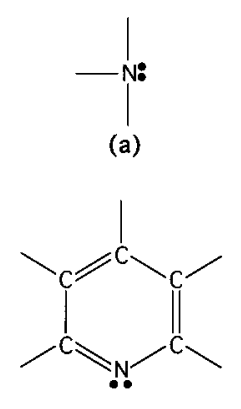

(d) Pyrridine

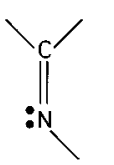

(g)

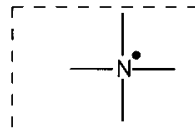

(b)

(c)

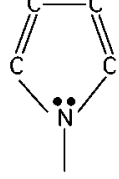

(e)

(f) Pyrrole

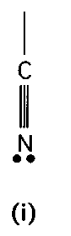

FIG. 1. Possible configurations of nitrogen in a-C:H:N. The lines represent bonds, dots are unpaired electrons, and dot pairs are lone pairs.

$\mathrm{N}$ does act as a substitutional donor in ta- $\mathrm{C}$ and ta- $\mathrm{C}: \mathrm{H}$, but its role in a-C:H is less clear.

In fact, ta-C: $\mathrm{H}$ differs from conventional a-C: $\mathrm{H}$ in two ways. It has a higher $\mathrm{sp}^{3}$ content, and a lower $\mathrm{H}$ content. ${ }^{16}$ It has recently been observed that a-C:H with a much lower $\mathrm{H}$ content could be prepared by plasma deposition from a conventional higher pressure plasma by employing magnetic confinement to increase the plasma ionization. ${ }^{18-20}$ This form of a-C:H is found to have a lower $\mathrm{H}$ content than ta$\mathrm{C}: \mathrm{H}$, but only a moderate $\mathrm{sp}^{3}$ content. It is therefore of interest to study the ability to dope it with nitrogen.

A further motivation for this work is the possible use of diamond and diamondlike carbon as thin film cold cathodes in field emission displays, ${ }^{21}$ because of their low electron affinities. Field emission from diamond films frequently increases as the crystal quality of the diamond decreases, ${ }^{22}$ presumably because of the need for a conduction path along the grain boundaries. There is clearly a need for an $n$ - type dopant for diamond, but $\mathrm{N}$ is deep $(1.4 \mathrm{eV})$ while other group $\mathrm{V}$ elements are insoluble. In contrast, $\mathrm{N}$ can in principle form shallow levels in a-C(:H) because of its smaller band gap. This causes the field emission from the a-C:H films studied in this article to increase by over one hundred by the addition of nitrogen. ${ }^{23}$

The analysis of the effect of $\mathrm{N}$ in a-C:H is complicated by the ability of $\mathrm{N}$ to adopt a variety of different bonding configurations, ${ }^{24,25}$ such as those shown in Fig. 1. In Fig. 1, valence electrons are either paired in bonds (shown as a line), unpaired (a dot), or paired in a nonbonding "lone pair" state (shown as two dots). Nitrogen has five valence electrons. In its simplest trivalent configuration (a), $\mathrm{N}$ forms three $\sigma$ bonds with the remaining two electrons in a lone pair. This is nondoping and is the stable configuration of $\mathrm{N}$ to be found in $\mathrm{Si}_{3} \mathrm{~N}_{4}$. N at a fourfold coordinated "substitutional" site (b) uses four electrons in $\sigma$ bonds and the fifth is unpaired and available for doping. A variant of this (c), forms a trivalent $\mathrm{C}$ site and transfers the unpaired electron to the $\mathrm{C}$, to give a positive $\mathrm{N}^{+} / \mathrm{C}^{-}$defect pair. This group has all electrons paired, like the analogous group in a-Si:H. ${ }^{26}$ There are other configurations, because $\mathrm{N}$ can also form $\pi$ bonds. $\mathrm{N}$ can substitute for $\mathrm{C}$ in a benzene ring [(d)/(e)]. Nitrogen can have just two neighbors within the ring, using three bonding electrons ( $2 \sigma$ and one $\pi$ ), leaving two electrons as a lone pair, Fig. 1(d). This pyrridine configuration is nondoping. Alternatively (e), three can form $\sigma$ bonds, a fourth forms a $\pi$ bond (as in benzene), and the fifth is unpaired and enters an antibonding $\pi^{*}$ state. This electron is available for " $\pi$ " doping. Another alternative (f) is for the $\mathrm{N}$ to have to bond to three neighbors, as in (e), but in a five-fold ring, ${ }^{24}$ so it uses three electrons in bonds and two as a lone pair. This "pyrrole" configuration is also nondoping. There are also olefinic variants of $\pi$ bonding. A double bonded unit (g) uses two electrons in $\sigma$ bonds, one in a $\pi$ bond, leaving a lone pair. This is nondoping. A double bonded unit (h) uses three electrons in $\sigma$ bonds, one in a $\pi$ bond, and the fifth in a nonbonding $\pi^{*}$ state, available for doping. The last configuration is a "chain terminating" cyano (or nitrile) grouping (i), in which $\mathrm{N}$ forms a triple bond and a lone pair. This in nondoping. It is relatively stable, being related to that found in the $\mathrm{N}_{2}$ molecule itself. This variety of configurations available for $\mathrm{N}$, most of which are nondoping, indicates why $\mathrm{N}$ is likely to be a weak dopant and why the behavior of $\mathrm{N}$ in a-C(:H) needs careful analysis.

\section{EXPERIMENT}

The nitrogenated a-C:H (a-C:H:N) films were deposited in a magnetically confined rf plasma enhanced chemical vapor deposition (PECVD) system. ${ }^{19}$ The substrate was placed on the rf powered electrode which acquires a negative dc self-bias voltage. This causes an ion bombardment of the growing film which is believed to be responsible for creating the $\mathrm{sp}^{3}$ bonding. An encased permanent rare earth magnet (Nd-B-Fe) is used around the substrates to increase the plasma density. The deposition was carried out at a fixed pressure of 0.1 Torr from a $\mathrm{CH}_{4}, \mathrm{He}$, and $\mathrm{N}_{2}$ gas mixture, with flow rates of $5 \mathrm{sccm}$ for $\mathrm{CH}_{4}, 45 \mathrm{sccm}$ for $\mathrm{He}$, and 0-20 sccm for $\mathrm{N}_{2}$. The magnetic field and the He increases the ionization of the methane plasma, giving a plasma electron temperature of over $6 \mathrm{eV}$, which results in a higher deposition rate and a lower bias voltage for a given rf power. The substrate temperature was maintained at $20^{\circ} \mathrm{C}$, although the surface temperature was seen to vary from $30-100^{\circ} \mathrm{C}$ depending on the rf power. The a-C:H:N films were deposited on $\{100\} \mathrm{Si}$ and quartz substrates.

The composition of the a-C:H:N films was determined by a combination of elastic recoil detection analysis (ERDA), Rutherford backscattering (RBS), and nuclear reaction analysis (NRA). The $\mathrm{N}$ content was found using the ${ }^{14} \mathrm{~N}(d, p){ }^{15} \mathrm{~N}$ nuclear reaction. Infrared (ir) spectra were collected at room temperature on a Mattson FTIR spectrometer. Raman spectroscopy measurements were conducted in the back scattering mode using an Ar laser (wavelength $488 \mathrm{~nm}$ ) operating at a power of $300 \mathrm{~mW}$. The scattered radiation was 
analyzed with a $1 \mathrm{~m}$ focal length double-pass monochromator (Yobin-Yvon, Ramanor model HG2-S) equipped with holographic gratings (2000 lines per $\mathrm{mm}$ ), and was detected by a cooled $\left(-35^{\circ} \mathrm{C}\right) \mathrm{GaAs}$ photomultiplier tube (RCA, Model C31034A-02), operated in photon counting mode. The monochromator stokes Raman spectra were recorded between 500 and $3000 \mathrm{~cm}^{-1}$ and stored in a multichannel analyzer. Optical absorption spectra were derived from transmission and reflection measurements on a Philips uv-VIS spectrometer in the wavelength range $200-900 \mathrm{~nm}$. The conductivity was measured using metal-carbon-metal sandwich structures using $\mathrm{Au}$ and $\mathrm{Al}$ electrodes evaporated onto the samples at pressures better than $10^{-6}$ Torr. Electron spin resonance (ESR) studies were performed on a Bruker EPR machine such that the signal did not saturate. The microwave power was varied between $200 \mu \mathrm{W}$ and $2 \mathrm{~mW}$ using a microwave frequency of $9.3 \mathrm{GHz}$. The modulation amplitude was $0.9 \mathrm{G}$ using a modulation frequency of $100 \mathrm{KHz}$.

Transmission electron microscopy (TEM) samples were prepared by dissolving the $\{100\} \mathrm{Si}$ substrate in a $\mathrm{HF}: \mathrm{HNO}_{3}$ deionized water solution and releasing the a-C:H:N samples. These films were then floated onto $\mathrm{Cu}$ grids. Electron energy loss spectra (EELS) were measured on a VG501 scanning transmission electron microscope (STEM) operated at $100 \mathrm{KeV}$. The spectra were acquired on a dedicated parallel EELS detector with a collection angle of $10 \mathrm{mrad}$ and an energy resolution of $0.6 \mathrm{eV}$. The specimen thickness was kept constant $(60-80 \AA)$ with the EELS spectra collected over an area of approximately $100 \mathrm{~nm}$ diam. The collected data was corrected for multiple scattering using the log ratio method. ${ }^{27}$ Low loss spectra were also measured to derive the valence plasmon energy and the joint density of states. Typical collection times for the low loss region was under $1 \mathrm{~s}$ and $30 \mathrm{~s}$ for the high energy region. The low loss region was then analyzed in terms of dielectric model which allowed the extraction of the real and imaginary parts of the dielectric function. This allowed the extraction of the optical conductivity or joint density of states (JDOS). ${ }^{28}$

\section{RESULTS}

\section{A. Composition and growth}

The variation of $\mathrm{H}$ and $\mathrm{N}$ content of the a-C:H films as a function of nitrogen gas flow ratio, $R=\left[\mathrm{N}_{2}\right] /\left[\mathrm{CH}_{4}\right]$ is shown in Fig. 2. The $\mathrm{N}$ content is seen to increase quite rapidly up to $R=1$, and then increase more gradually. The data shows that the incorporation ratio is much less than one, presumably because $\mathrm{N}$ is less easily ionized than $\mathrm{CH}_{4}$. Although the ionization potential of $\mathrm{N}_{2}$ is $11.1 \mathrm{eV}$, in order to get $\mathrm{N}^{+}$ions an energy of $14.5 \mathrm{eV}$ is required. To generate $\mathrm{CH}_{4}^{+}$and $\mathrm{CH}_{3}^{+}$species from the $\mathrm{CH}_{4}$ molecule, ionization energies of 12.6 and $14.3 \mathrm{eV}$ are required. The $\mathrm{H}$ content of undoped a-C:H is 21 at $\%$. This value decreases gradually with $\mathrm{N}$ incorporation, up to a gas flow ratio of 1.0, and it then falls more rapidly.

The growth rate depends strongly on $\mathrm{N}$ addition, and it appears to decrease in a roughly exponential fashion until an

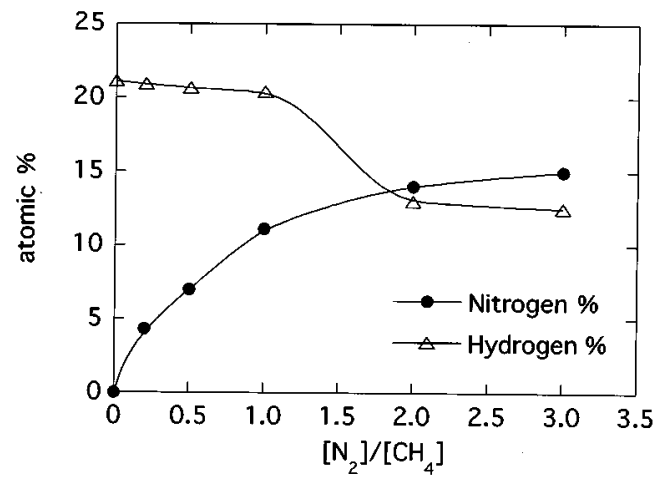

FIG. 2. Variation of nitrogen and hydrogen content of a-C:H:N films with $\mathrm{N}_{2}$ gas flow ratio.

atomic $\mathrm{N}$ content of 3\%, as seen in Fig. 3(a). After this, the decrease in growth rate is more gradual.

Compressive stress is an intrinsic feature of films grown here under conditions of ion bombardment. The compressive stress was derived using the method proposed by Argon et al. ${ }^{29}$ based on the change in curvature of the substrate using Stoney's equation. The variation of the stress as a function of atomic $\mathrm{N}$ content is shown in Fig. 3(b). The stress is seen to decrease with $\mathrm{N}$ content. The lower stress at higher $\mathrm{N}$ contents is desirable, as it allows thicker, adherent films to be deposited. The maximum thickness increases from about $400 \mathrm{~nm}$ for a-C:H (non-nitrogenated) to over $1 \mu \mathrm{m}$ for 15 at. $\% \mathrm{~N}$ content.

\section{B. Transmission electron microscopy and electron energy loss spectroscopy}

The TEM studies of the a-C:H:N films show them to be completely amorphous with no crystalline inclusions. Two diffused rings centred at 2.1 and $1.1 \AA$ are seen in diffraction mode which correspond to amorphous carbon. ${ }^{30}$ The structure of the film changes dramatically when the $\mathrm{N}$ content

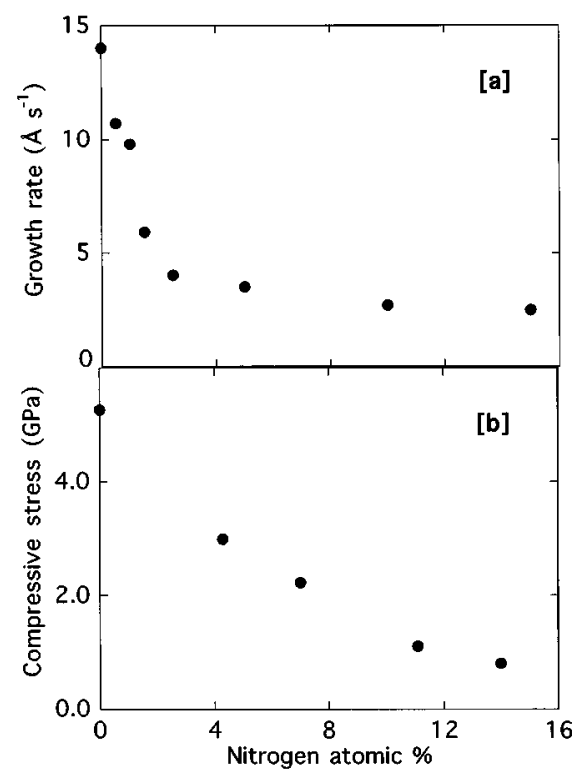

FIG. 3. (a) Growth rate and (b) compressive stress of a-C:H:N films vs $\mathrm{N}$ content. 


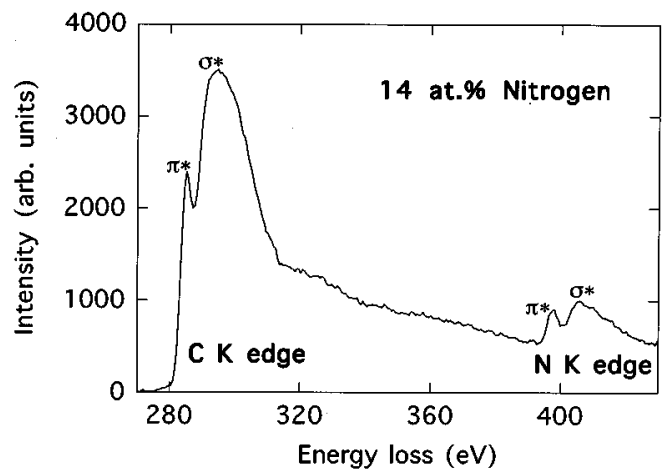

FIG. 4. Typical EELS spectrum for a-C:H:N with the assignment of prominent bands.

exceeds a threshold of 14 at.\%. At low $\mathrm{N}$ content, the films are extremely smooth, with peak-to-peak roughness of less than $5 \mathrm{~nm}$ over atomic force microscopy (AFM) scans of $1 \mu \mathrm{m}$. For $\mathrm{N}$ contents over $14 \%$, the surface becomes rougher, with amorphous nodulelike surface features with average heights of $20 \mathrm{~nm}$ and diameters of $50 \mathrm{~nm}$.

The nature of the $\mathrm{C}$ and $\mathrm{N}$ bonding was derived from EELS. The spectrum consists of absorption edges for each element's core level, and the absorption just above the edge is proportional to the local density of conduction states about that atom. The carbon $K$ edge consists of a step at $290 \mathrm{eV}$ due to transitions from the $\mathrm{C} 1 \mathrm{~s}$ core level to $\sigma^{*}$ states and a peak at $285 \mathrm{eV}$ due to transitions to $\pi^{*}$ states of $\mathrm{sp}^{2}$ sites (and $\mathrm{sp}^{1}$ sites). The $\mathrm{N} K$ edge spectrum appears around 400 $\mathrm{eV}$ and consists of a similar step and peak features, ${ }^{15}$ Fig. 4. The $\mathrm{C} \mathrm{sp}{ }^{2}$ fraction can be deduced from the $\mathrm{C} K$ edge, as the ratio of the area of the $285 \mathrm{eV}$ peak to the $290 \mathrm{eV}$ step, normalized to its value in fully $\mathrm{sp}^{2}$ graphitic $\mathrm{C}$. This same ratio is then assumed to apply to that for $\mathrm{sp}^{2} \mathrm{~N}$ sites. The EELS spectrum could also be used to derive the N/C composition.

The variation of $\mathrm{sp}^{2}$ fraction for $\mathrm{C}$ and $\mathrm{N}$ sites as a function of $\mathrm{N}$ content is shown in Figs. 5(a) and 5(b). The $\mathrm{C}$ $\mathrm{sp}^{3}$ fraction is seen to remain within the range $30-40 \%$ up to a $\mathrm{N}$ content of 7 at.\%, where the $\mathrm{sp}^{3}$ fraction reaches a maximum of $45 \%$, and then it decreases gradually to $20 \% \mathrm{sp}^{3}$ content at 14 at. $\% \mathrm{~N}$. The latter fall corresponds to graphitization which usually occurs at high $\mathrm{N}$ content. The $\mathrm{sp}^{2}$ fraction at $\mathrm{N}$ sites varies more dramatically. At low $\mathrm{N}$ content, the $\mathrm{N} \mathrm{sp}^{3}$ fraction is low. It then rises sharply to about $80 \%$ of $\mathrm{N}$ sites at $7 \% \mathrm{~N}$, and it then decreases again to about $40 \%$ at higher $\mathrm{N}$ contents. This result is one of a number to indicate that $7 \% \mathrm{~N}$ is a critical composition.

The valence plasmon energy was also measured by EELS, and used to derive a value for the mass density. The plasmon is $22.8 \pm 0.3 \mathrm{eV}$ across the range of $\mathrm{N}$ contents.

\section{Infrared spectroscopy}

The local bonding of $\mathrm{C}, \mathrm{H}$, and $\mathrm{N}$ sites can be deduced from a representative infrared absorption spectrum as shown in Fig. 6. The spectra can be divided into four regions, the $\mathrm{C}-\mathrm{C}, \mathrm{C}-\mathrm{H}$ and $\mathrm{C}-\mathrm{N}$ modes from 0 to $1700 \mathrm{~cm}^{-1}, \mathrm{C} \equiv \mathrm{N}$ stretching modes from 2065 to $2260 \mathrm{~cm}^{-1}, \mathrm{C}-\mathrm{H}$ stretching

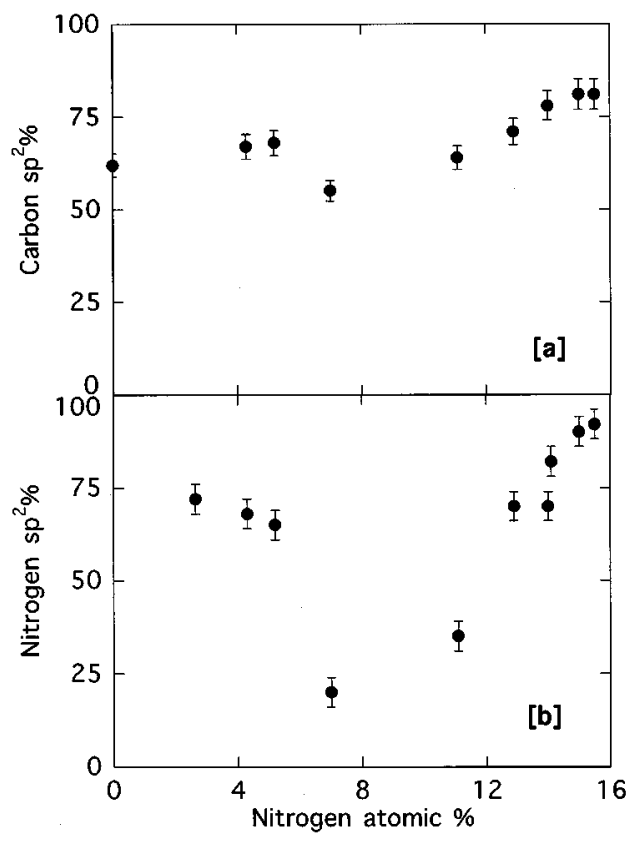

FIG. 5. (a) Carbon and (b) nitrogen $\mathrm{sp}^{2}$ fraction of a-C:H:N films vs $\mathrm{N}$ content.

modes from 2700 to $3100 \mathrm{~cm}^{-1}$, and $\mathrm{N}-\mathrm{H}$ stretching modes from 3150 to $3400 \mathrm{~cm}^{-1}$, according to assignments in molecules. ${ }^{31}$

The variation of the intensity of these modes as a function of $\mathrm{N}$ content is shown in Fig. 7. The intensities of the $\mathrm{C}-\mathrm{H}$ stretching modes are seen to decline rather rapidly with increasing $\mathrm{N}$ content. These modes are assigned to vibrations of $\mathrm{sp}^{3}$ and $\mathrm{sp}^{2}$ sites. Notice that $\mathrm{sp}^{1}$ sites would introduce modes around $3300 \mathrm{~cm}^{-1} \cdot 31,32$ The finite value of modes around $3300 \mathrm{~cm}^{-1}$ in $\mathrm{N}$-free films indicates a contribution from $\mathrm{H}-\mathrm{C} \equiv \mathrm{C}$ - groups as well as $=\mathrm{N}-\mathrm{H}$ groups. Infrared peaks observed at $2325 \mathrm{~cm}^{-1}$ in cathodic arc deposited a-C(:N) films by Merchant et al. ${ }^{33}$ has also been ascribed to triple bonded carbon.

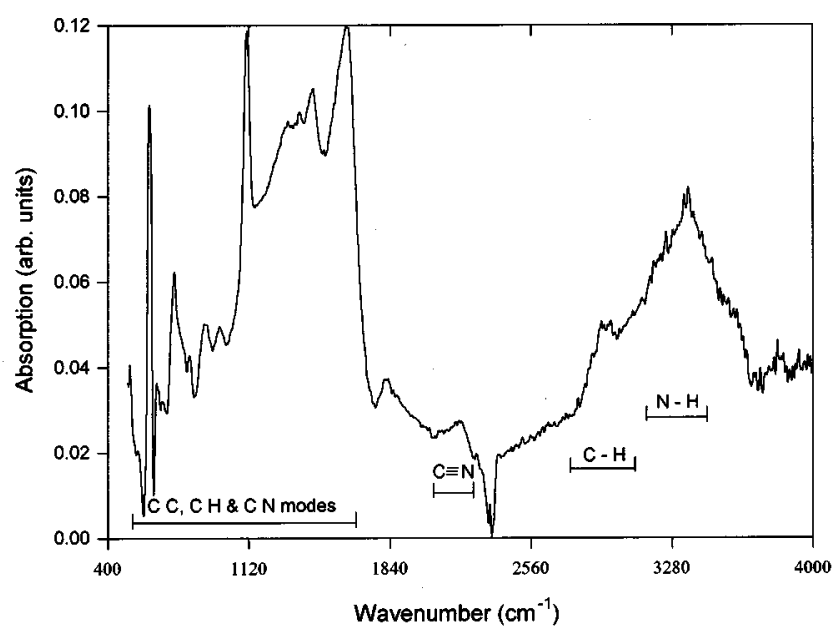

FIG. 6. Typical infrared spectrum for a-C:H:N with the assignments of prominent bands in an a-C:H:N film with an atomic $\mathrm{N}$ content of $11 \%$. 


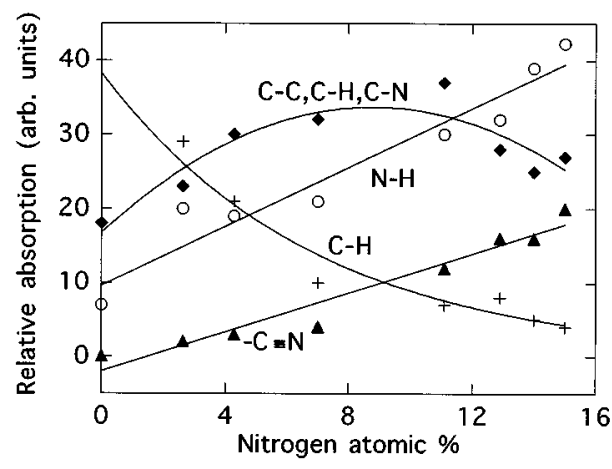

FIG. 7. Variation of the ir band intensities vs $\mathrm{N}$ content.

The intensity of the $\mathrm{N}-\mathrm{H}$ modes at $3140-3350 \mathrm{~cm}^{-1}$ is seen to increase rapidly with $\mathrm{N}$ content. Similar modes ascribed to N-H modes in the data of Kaufman et al. ${ }^{34}$ can be associated with an increase in $\mathrm{N}-\mathrm{H}$ bonds.

The modes below $1700 \mathrm{~cm}^{-1}$ are particularly interesting. The $\mathrm{C}-\mathrm{C}$ stretching modes lie up to about $1350 \mathrm{~cm}^{-1}$ for $\mathrm{sp}^{3} \mathrm{C}$, up to $1600 \mathrm{~cm}^{-1}$ for aromatic $\mathrm{sp}^{2} \mathrm{C}$ and up to $1700 \mathrm{~cm}^{-1}$ for olefinic $\mathrm{sp}^{2} \mathrm{C}$. The $-\mathrm{NH}_{2}(1650-1560$ $\left.\mathrm{cm}^{-1}\right),>\mathrm{NH}\left(1580-1490 \mathrm{~cm}^{-1}\right),-\mathrm{NH}_{3}^{+} \quad(1600$ and $\left.1500 \mathrm{~cm}^{-1}\right), \quad>C=N-\left(1690-1640 \mathrm{~cm}^{-1}\right), \quad-\mathrm{N}=\mathrm{N}-$ $\left(1575 \mathrm{~cm}^{-1}\right)$ groups also may make a contribution to these modes, but is unlikely to be of significant magnitude especially at low $\mathrm{N}$ contents. In a-C(:H) the $\mathrm{C}-\mathrm{C}$ modes are not ir active (only Raman active), because the $\mathrm{C}-\mathrm{C}$ bond is not polar. However, in a-C:H:N, the introduction of polar $\mathrm{C}-\mathrm{N}$ bonds may render these modes ir active. ${ }^{34}$ Moreover, as the modes are delocalized, particularly around aromatic rings, the $\mathrm{N}$ atoms tend to make all modes to an extent ir active. For example, the $\mathrm{N}$ atom in the pyrridine ring, Fig. 1(d), will make all the modes of a distorted ring ir active. Figure 7 shows that the intensity of the $1500-1785 \mathrm{~cm}^{-1}$ modes, which is one of the dominant peaks in this region, first increases and then decreases with increasing $\mathrm{N}$ content. The increase corresponds to the increasing oscillator strength of mixed $\mathrm{C}-\mathrm{C}-\mathrm{N}$ modes of both aromatic and olefinic units. The decrease presumably corresponds to a fall in the concentration of aromatic and olefinic groups due to an increase in cyano (nitrile) groups at high $\mathrm{N}$ contents. The offset observed in the data confirms the fact that the $\mathrm{C}-\mathrm{C}$ stretching modes dominate initially with any consequent changes arising from the $\mathrm{C}-\mathrm{C}-\mathrm{N}$ modes.

Modes at $2065-2260 \mathrm{~cm}^{-1}$ correspond to the terminating cyano (nitrile) group $-\mathrm{C} \equiv \mathrm{N}$, Fig. 1(i), the intensity of which is seen to rise rapidly with increasing $\mathrm{N}$ content in Fig. 7. There are no corresponding modes of $\mathrm{C}$ atoms in this range. Schwan et $a l^{10}$ also found a rapid increase in the $\mathrm{C} \equiv \mathrm{N}$ and $\mathrm{C}=\mathrm{N}$ bonded modes in their plasma deposited a-C:H(:N) films with increasing $\mathrm{N}$ content in the source gases.

\section{Raman spectroscopy}

Raman spectroscopy is a widely used technique to characterize amorphous and noncrystalline carbons. The Raman spectrum of a noncrystalline $\mathrm{C}$ in general consists of two

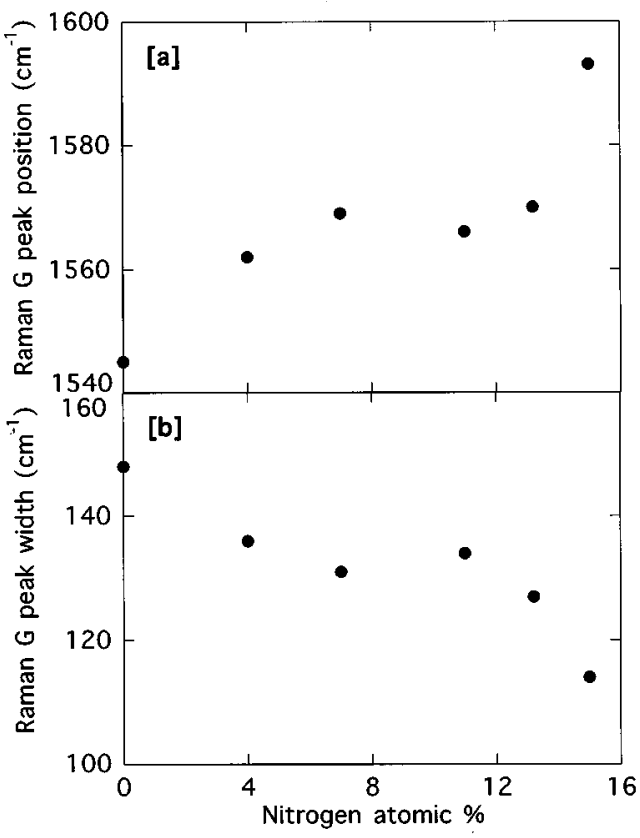

FIG. 8. Variation of (a) peak position $\omega_{G}$ and (b) width $\Gamma_{G}$ of the Raman $G$ peak with $\mathrm{N}$ content.

features, a $G$ peak at around $1550 \mathrm{~cm}^{-1}$ due to optical zone center vibrations $\left(\mathrm{E}_{2 g}\right.$ mode) in graphite of aromatic rings, and a $D$ peak or shoulder around $1360 \mathrm{~cm}^{-1}$, due to the disorder activated optical zone edge modes of microcrystalline graphitic sheets. The modes of $\mathrm{sp}^{3}$ bonding in a-C tend not to show up in Raman, because of their low scattering cross-section. Tamor and Vassel ${ }^{35}$ have provided a useful empirical correlation of the position, width, and intensity ratio of the $G$ and $D$ peaks to the properties of a-C(:H). The Raman spectra of our films were quantitatively analyzed using a computer code in order to reproduce the data as a sum of two Gaussians. ${ }^{36}$ The position, width, and intensity of each line were assumed as fitting parameters and the least square fit of the experimental data was attempted. Figure 8 shows that the position of the $G$ peak, $\omega_{G}$, increases with $\mathrm{N}$ content. This generally corresponds to increasing graphitic character in a-C:H. ${ }^{35,36}$ The width of the $G$ peak $\Gamma_{G}$ decreases with increasing $\mathrm{N}$ content. $\Gamma_{G}$ is a measure of the network disorder, as it is in a-Si, and its reduction is consistent with the fall in stress with $\mathrm{N}$ content seen in Fig. 3(b). The position of the $G$ band shifts to higher frequency and its bandwidth decreases. These results show that $\mathrm{N}$ incorporation in the a-C:H films favor the formation of $\mathrm{sp}^{2}$ units according to the Raman data. These microstructural modifications (and decrease in the average coordination number) may account for the observed reduction in the internal stress of these films. ${ }^{10,37}$

\section{E. Optical properties}

The variation of the optical (Tauc) gap as a function of $\mathrm{N}$ content is shown in Fig. 9(a). The optical gap is seen to increase from $1.65 \mathrm{eV}$ in a-C:H itself up to $2.10 \mathrm{eV}$ at $7 \% \mathrm{~N}$. The gap then decreases slightly as the $\mathrm{N}$ content rises from $7 \%$ to $14 \%$. The latter decline is presumably due to the in- 


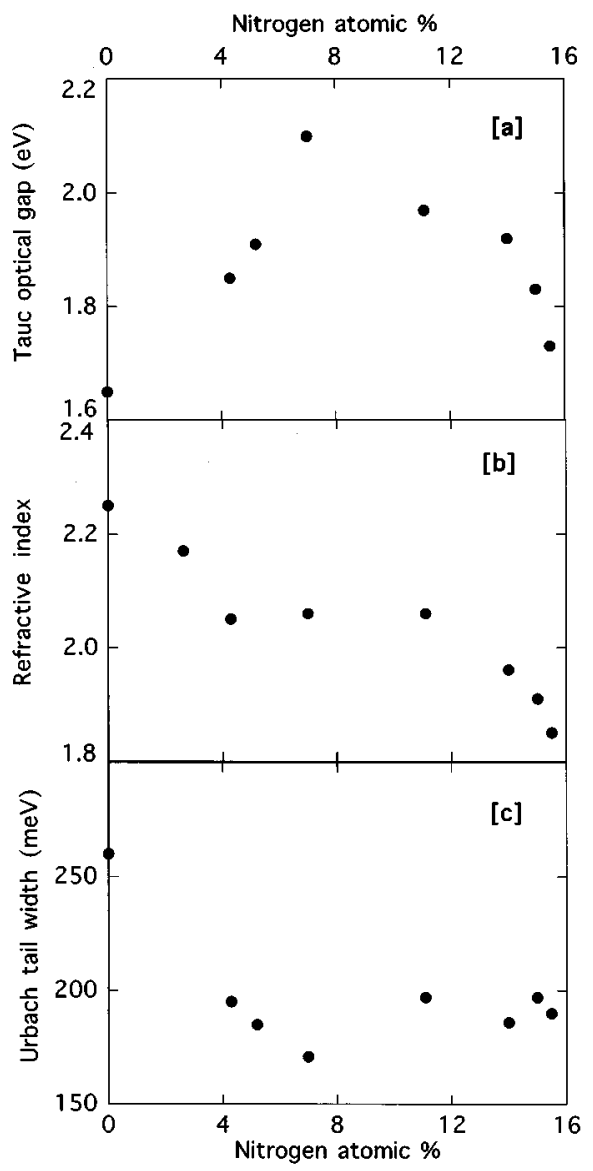

FIG. 9. (a) Optical gap, (b) refractive index, and (c) Urbach tail energy of a-C:H:N films vs $\mathrm{N}$ content.

creased $\mathrm{sp}^{2}$ fraction induced by the addition of N, Fig. 5(a). The local maximum in the gap at $7 \% \mathrm{~N}$ is further indication of a critical composition.

The refractive index shown in Fig. 9(b) generally declines with increasing $\mathrm{N}$ content. The refractive index is related to the average of "Penn" band gap $E_{g}$ and the plasmon energy $E_{p}$ by the Penn model, ${ }^{38}$

$$
n^{2}-1=\varepsilon_{0}-1=E_{p}^{2} / E_{g}^{2} .
$$

It has already been noted that the plasmon energy remains constant at $22.8 \mathrm{eV}$ with $\mathrm{N}$ content, according to the low loss EELS. Thus, the Penn gap increases with increasing $\mathrm{N}$ content. The average gap corresponds to the average bonding antibonding splitting and is much larger than the minimum optical gap. The average gap of a-C:H from Eq. 1 is $11.3 \mathrm{eV}$. This is less than for diamond, $13.6 \mathrm{eV}$, because of the presence of $\pi$ states which have a narrower gap. The average band gap is expected to increase with $\mathrm{N}$ incorporation as the bonding acquires a polar content.

The width of the optical absorption edge shown in Fig. 9 (c), the Urbach energy $E_{0}$, declines with increasing $N$ content up to $7 \%$ and then remains relatively constant. The Urbach energy is a measure of the disorder of the atomic network. This decrease suggests that the disorder of a-C:H:N

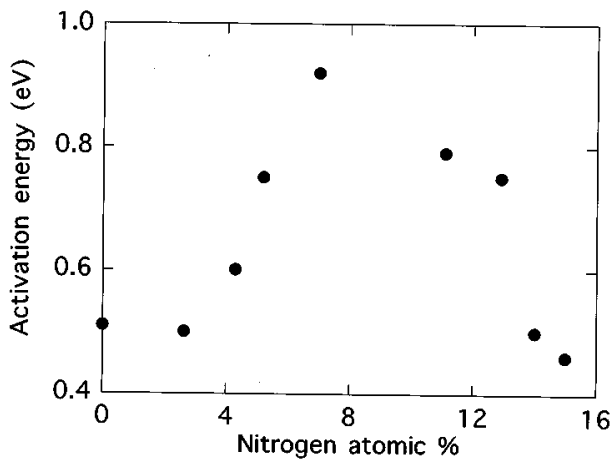

FIG. 10. Conductivity activation energy $\Delta E$ vs $\mathrm{N}$ content.

may reduce with initial addition of $\mathrm{N}$. This is the only case known to the authors of alloying actually decreasing disorder.

\section{F. Electrical characterization}

The activation energy $\Delta E$ of conductivity of a-C:H:N was derived from an Arrhenius plot of conductivity versus inverse temperature. The Arrhenius plot shows two straight line regimes, one in the temperature range $40-100{ }^{\circ} \mathrm{C}$, and the other between the temperatures of $100-200{ }^{\circ} \mathrm{C}$. The variation of $\Delta E$ shown in Fig. 10 is for temperatures greater than $100{ }^{\circ} \mathrm{C}$. The conduction mechanism for temperatures below $100^{\circ} \mathrm{C}$ in a-C:H:N films, where $\Delta E$ varies from 0.34 to $0.55 \mathrm{eV}$ in a similar manner to that shown in Fig. $10,{ }^{20}$ is attributed to localized tail states. Above $100{ }^{\circ} \mathrm{C}$, thermally activated conduction predominates. For a-C:H:N, which is an amorphous material, the mobilities of electrons and holes at the band edge states are assumed to be similar.

$\Delta E$ for a-C:H $(0.5 \mathrm{eV})$ is considerably less that half the optical gap $(1.65 \mathrm{eV}) . \Delta E$ then increases to a value of $0.9 \mathrm{eV}$ at $7 \% \mathrm{~N}$. This is much closer to half the optical gap at this composition $(2.1 \mathrm{eV}) . \Delta E$ then declines to $0.46 \mathrm{eV}$ at $15 \%$ $\mathrm{N}$, which is again much less than half the gap $(1.8 \mathrm{eV})$ at that composition. We interpret this as follows. $\Delta E$ corresponds to the energy difference from $E_{F}$ to the conduction level, usually the nearest band edge. $E_{F}$ in conventional a-C:H tends to lie near midgap. ${ }^{2}$ However, $E_{F}$ in ta-C and ta-C:H appears to lie well below midgap, as summarized in the introduction. This arises because half-filled $\mathrm{C}$ defect levels lie predominantly below midgap. We believe that the present a-C:H, also with a low $\mathrm{H}$ content, has a similar behavior, with its $E_{F}$ below midgap. In that case, if $\mathrm{N}$ is a weak donor, $\mathrm{N}$ addition causes $E_{F}$ to rise through the gap towards $E_{C}$. This accounts in general terms for the increase and then decrease of $\Delta E$ in Fig. 10. The 7\% $\mathrm{N}$ composition is the compensated composition, where the $\mathrm{N}$ donors compensate the acceptorlike defects. This situation is locally stable, and perhaps accounts for why the fraction of $\mathrm{N} \mathrm{sp}^{3}$ bonding reaches a maximum there.

The alternative interpretation, that the activation energy change arises simply from changes in the gap, is rejected because the conductivity changes are consistent with the strong changes in the bonding at $\mathrm{N}$ sites shown in Fig. 5. 


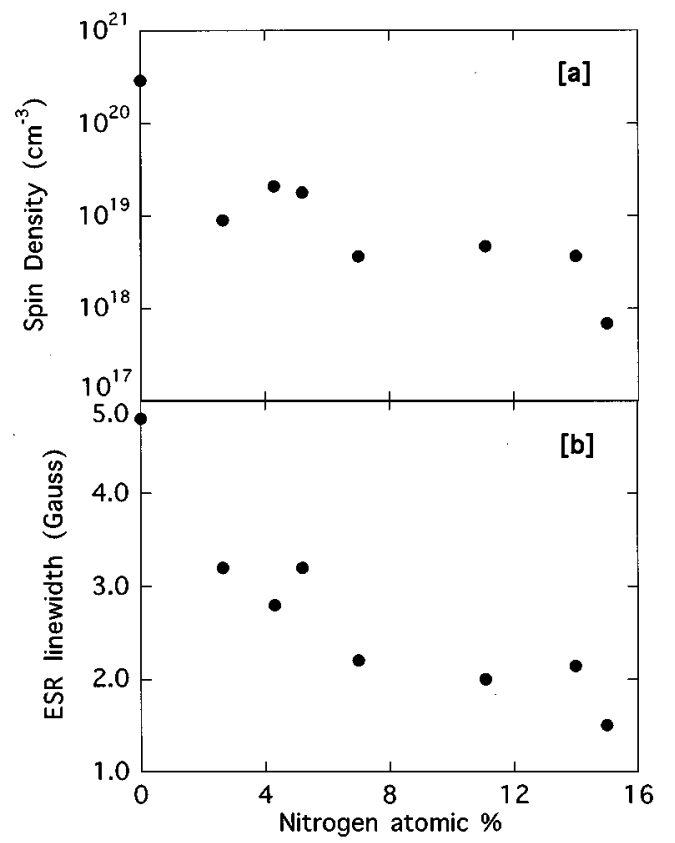

FIG. 11. (a) Spin density and (b) ESR line width $\mathrm{H}_{p p}$ vs $\mathrm{N}$ content.

The compensation occurring at such a high composition as $7 \%$ emphasises the low doping efficiency of $\mathrm{N}$ in a-C:H. In essence, the addition of $7 \% \mathrm{~N}$ atoms has moved $E_{F}$ through a defect density of say $4 \times 10^{18}-4 \times 10^{20} \mathrm{~cm}^{-3}$ (see Sec. III G), so the efficiency is given by $10^{20} /\left(0.07 \mathrm{~N}_{a t}\right)$ or $0.02 \%-1.5 \%$, where $\mathrm{N}_{a t}$ is the atomic density, $3.7 \times 10^{23} \mathrm{~cm}^{-3}$ derived from the valence plasmon energy. There are many possibilities for the nature of the $\mathrm{N}$ donor level, from Figs. 1(b), 1(c), 1(e), and 1(h).

\section{G. Electron spin resonance}

Various bonding configurations give rise to states in the gap, which when half-filled and paramagnetic gives rise to an electron spin resonance (ESR) signal. The variation of this spin density as a function of atomic $\mathrm{N}$ content is shown in Fig. 11. The spin density decreases rapidly from a high value of $4 \times 10^{20} \mathrm{~cm}^{-3}$ to values below $10^{18} \mathrm{~cm}^{-3}$ with increasing $\mathrm{N}$ content.

There are two possible reasons for the decrease in spin density, either the total defect density has decreased, or the defects have been converted from their paramagnetic to diamagnetic configuration by the transfer of electrons from $\mathrm{N}$ sites. Generally, diamagnetic defects are expected in the presence of dopants, because the donor electrons will fall down from the donor level into the singly occupied defect level and make it fully occupied and diamagnetic. A typical example of this situation is the diamagnetic $\mathrm{N}_{4}^{+}-\mathrm{C}_{3}^{-}$configuration shown in Fig. 1(c). This effect has been shown to occur in a-Si:H. ${ }^{26}$

On the other hand, the total defect density is correlated with the network disorder and Urbach slope, as occurs in a-Si:H. Thus the decrease in Urbach slope seen in Fig. 9(c) suggests that at least part of the decrease in spin density is due to a decrease in the total defect density. If so, this is a remarkable decrease. We hope to confirm this by measuring

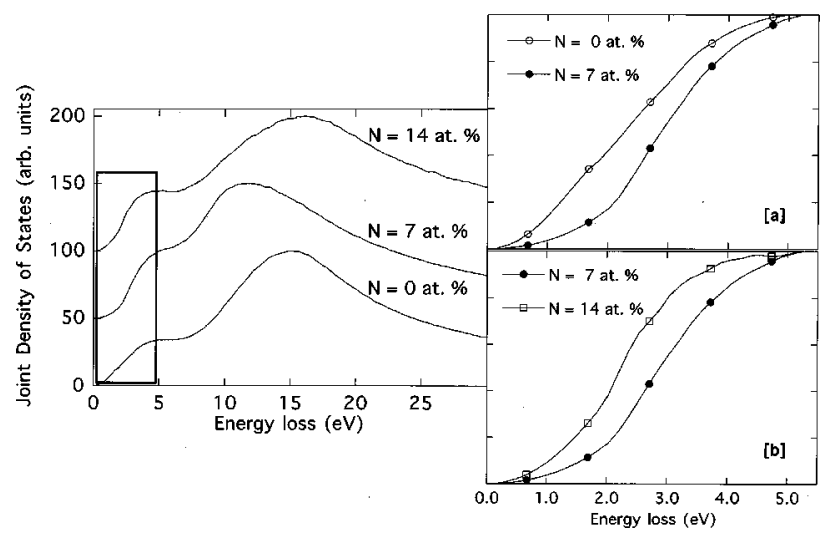

FIG. 12. Joint density of states from EELS.

the total defect density by light induced ESR, in which all defects are excited to their paramagnetic state.

The nature of the defect configuration can often be identified from the ESR g-factor and linewidth. A g-factor of 2.0028 indicates a carbon center. ${ }^{39}$ The ESR linewidth in Fig. 11(b), shows it to decrease with increasing nitrogen content. The ESR linewidth in a-C:H films has been attributed to exchange narrowing. ${ }^{39-43}$ The linewidth under exchange narrowing is proportional to the electron density per site and so inversely proportional to the number of sites over which the unpaired electron is delocalized. The 2.0028 defect has been associated with $\mathrm{sp}^{2}$ clusters, ${ }^{43}$ so the decrease in linewidth with $\mathrm{N}$ content suggests that the defect becomes larger with increasing $\mathrm{N}$ content. The alternative line broadening mechanism in spin resonance is dipolar broadening by interaction with nearby $\mathrm{H}$ atoms, in which the linewidth would increase with $\mathrm{H}$ content. A dependence on $\mathrm{H}$ content was observed in sputtered a-C:H by Hoinkis et al. ${ }^{41}$ In our case, the linewidth decreases from 5 to $2 \mathrm{G}$ for $\mathrm{N}$ contents from $0 \%$ to $7 \%$, while the $\mathrm{H}$ content is essentially constant (Fig. 2), which is evidence against this dipolar broadening in PECVD a-C:H.

\section{DISCUSSION}

The variation of the JDOS as a function of $\mathrm{N}$ content is shown in Fig. 12. The area shown boxed in Fig. 12 is expanded in Figs. 12(a) and 12(b). The JDOS for all three films in general can be taken to consist of two broad peaks centered about 5 and $12 \mathrm{eV}$. The peak at $\sim 5 \mathrm{eV}$ is attributed to $\pi-\pi^{*}$ states and the one at $12 \mathrm{eV}$ to $\sigma-\sigma^{*}$ states. It is seen that there is a significant reduction in the gap states as the $\mathrm{N}$ content changes from $0 \%$ to $7 \%$, seen as a reduction in the JDOS in the $0-5 \mathrm{eV}$ region in Fig. 12(a). This is consistent with the widening of the optical gap and sharpening of band tails seen in Fig. 9. As the $\mathrm{N}$ content rises to $14 \%$, it is seen that the JDOS at the band edges now increases again. This is attributed to the introduction of extra states near the band edges by $\mathrm{N}$ sites.

In analyzing the electronic doping results, a model as to how a predominantly $\mathrm{sp}^{2}$ bonded material can contribute to the conduction process must be considered. If it is assumed that each of the $\mathrm{N}$ that is $\mathrm{sp}^{3}$ bonded to $\mathrm{C}$ contributes an electron to the conduction process when found sitting in a 


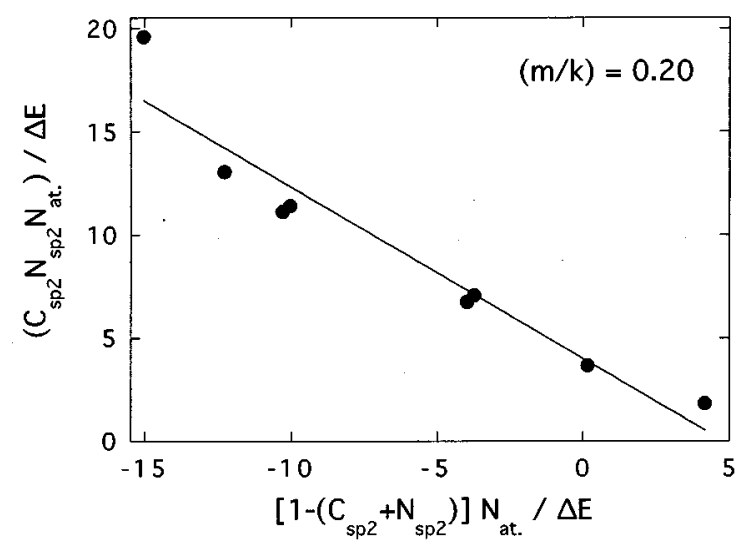

FIG. 13. The relative electronic doping efficiency of $\mathrm{N}$ in an $\mathrm{sp}^{2}$ and $\mathrm{sp}^{3}$ environment in a-C:H thin films (see text for details).

$\mathrm{sp}^{3} \mathrm{C}$ environment Fig. 1(b), and that the $\mathrm{N}$ which is $\mathrm{sp}^{2}$ bonded in a sp ${ }^{2} \mathrm{C}$ environment contributes an electron due to pairing up of the $\mathrm{C} \pi$ electron with the fourth $\mathrm{N}$ electron, Figs. 1(e) and 1(h), then an empirical expression which relates the electronic activation energy for conduction to the $\mathrm{C}$ and $\mathrm{N}$ bonding configuration can be derived.

$$
\begin{aligned}
{[(k} & \left.\left.\times \mathrm{N}_{\mathrm{sp}^{2}} \times \mathrm{C}_{\mathrm{sp}^{2}}\right)+\left(m \times \mathrm{N}_{\mathrm{sp}^{3}} \times \mathrm{C}_{\mathrm{sp}^{3}}\right)\right] \times \mathrm{N}_{\mathrm{at} .} \\
\quad= & \text { constant } \times \Delta E_{\text {intr }},
\end{aligned}
$$

where $k$ and $m$ are the electrically active doping efficiencies in the $\mathrm{sp}^{2}$ and $\mathrm{sp}^{3}$ bonding configurations and $\Delta E_{\text {intr }}$ the movement of the Fermi level from the undoped state. By using a suitable set of axes in the form shown in Fig. 13, $\left[\left(\mathrm{N}_{\mathrm{sp}^{2}} \times \mathrm{C}_{\mathrm{sp}^{2}} \times \mathrm{N}_{\mathrm{at} .} / \Delta E_{\mathrm{intr}}\right] \quad\right.$ versus $\left[1-\left(\mathrm{N}_{\mathrm{sp}^{2}} \times \mathrm{C}_{\mathrm{sp}^{2}} \times \mathrm{N}_{\mathrm{at} .} /\right.\right.$ $\Delta E_{\text {intr }}$, it is possible to obtain a measure for the relative efficiency of doping $(\mathrm{k} / \mathrm{m})$ in the two configurations. A suitable fit to the data shown in Fig. 13 gives a straight line approximation and a value for " $\mathrm{k} / \mathrm{m}$ " equivalent to 0.2 . The experimental data indicates that it is five times more likely that an $\mathrm{N}$ which substitutes in a $C_{\mathrm{sp}^{3}}$ environment acts as an active donor compared to an $\mathrm{N}$ which is in a $\mathrm{C}_{\mathrm{sp}^{2}}$ environment. This result also agrees with the experimental observation that highly tetrahedral a-C can be more easily and efficiently doped with $\mathrm{N}$ when compared to a-C:H:N films. In the results published by Veerasamy et al. ${ }^{14}$ an atomic $\mathrm{N}$ content of $0.5 \%$ was needed to shift the Fermi level to midgap in highly tetrahedral a-C, whereas an atomic $\mathrm{N}$ content of $7 \%$ is needed in the a-C:H:N thin films.

The compressive stress in the a-C:H:N films decreased with increasing $\mathrm{N}$ content, Fig. 3(b). This variation is evidence for structural relaxation due to the addition of $\mathrm{N}$. The stress in a thin film is a good indicator as to the constraints present in the bonding in a material. Thrope ${ }^{44}$ defined a mean coordination number $\langle r\rangle$ for a skeleton network in terms of the fraction of threefold, fourfold coordinated, and $\mathrm{H}$ sites in a network,

$$
\langle r\rangle=\frac{4 \mathrm{C}_{\mathrm{sp}^{3}}+3 \mathrm{C}_{\mathrm{sp}^{2}}-\mathrm{C}_{\mathrm{H}}}{1-\mathrm{C}_{\mathrm{H}}},
$$

where $\mathrm{C}_{\mathrm{sp}^{3}}$ is the carbon $\mathrm{sp}^{3}$ content, $\mathrm{C}_{\mathrm{sp}^{2}}$ is the carbon $\mathrm{sp}^{2}$ content and $\mathrm{C}_{\mathrm{H}}$ the hydrogen content in the a-C:H:N films.

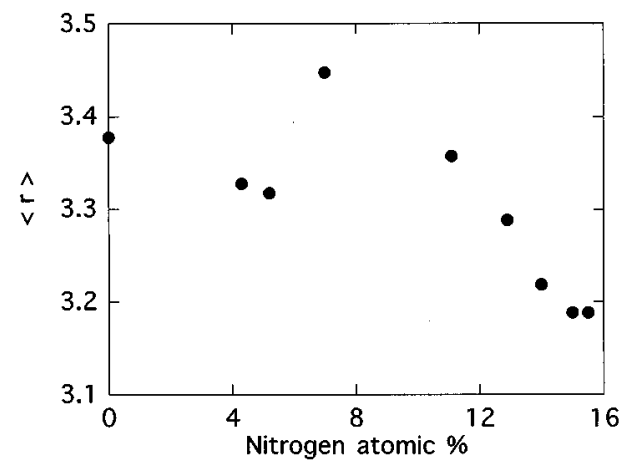

FIG. 14. Mean network coordination number vs N content.

Figure 14 shows the variation of the coordination number for the a-C:H:N thin films. The peak in the coordination number is seen to correspond to the maximum of the $\mathrm{C}$ and $\mathrm{N} \mathrm{sp}^{3}$ contents. The coordination of our a-C:H:N alloys decreases gradually with $\mathrm{N}$ content and rapidly beyond an atomic $\mathrm{N}$ content of $7 \%$. This is expected if the atomic $\mathrm{N}$ acts as a termination site and thereby relaxes the entire a-C:H:N network towards three. Since the optical band gap still remains relatively high, it is difficult to classify these films as graphitic in nature. As the $\mathrm{N}$ bonds preferentially in a threefold coordination in the $\mathrm{C}-\mathrm{N}$ alloys, the relative $\mathrm{N}$ content too should be considered before a classification is made as to the nature of the film.

\section{CONCLUSIONS}

The effect of nitrogen addition on the structural and electronic properties of hydrogenated amorphous carbon (a$\mathrm{C}: \mathrm{H})$ films has been characterized. The variation of conductivity with nitrogen content suggest that $\mathrm{N}$ acts as a weak donor, with the conductivity first decreasing and then increasing as the Fermi level moves up in the band gap. Compensated behavior is found at about 7 at. $\% \mathrm{~N}$, where various properties such as the optical gap, and $\mathrm{N} \mathrm{sp}^{3}$ content show a maximum. The Urbach energy and paramagnetic defect density are found to decrease with increasing $\mathrm{N}$ content. This indicates an unusual decrease in disorder with alloying.

${ }^{1}$ A. M. Liu and M. Cohen, Science 245, 841 (1989).

${ }^{2}$ B. Meyerson and F. W. Smith, Solid State Commun. 34, 531 (1980).

${ }^{3}$ B. Meyerson and F. W. Smith, Solid State Commun. 41, 68 (1982).

${ }^{4}$ D. I. Jones and A. D. Stewart, Philos. Mag. B 46, 423 (1982).

${ }^{5}$ O. Amir and R. Kalish, J. Appl. Phys. 70, 4958 (1991).

${ }^{6}$ A. Mansour and D. Ugolini, Phys. Rev. B 47, 4958 (1993).

${ }^{7}$ A. Helmbold, P. Hammer, J. U. Thiele, K. Rohwer, and D. Meissner, Philos. Mag. B 72, 335 (1995).

${ }^{8}$ O. Stenzel, M. Vogel, S. Ponitz, R. Petrich, and T. Wallendorf, Phys. Status Solidi A 140, 179 (1993).

${ }^{9}$ H. X. Han and B. J. Feldman, Solid State Commun. 65, 921 (1988).

${ }^{10}$ J. Schwan, W. Dworschak, K. Jung, and H. Ehrhardt, Diam. Relat. Mater. 3, 1034 (1994).

${ }^{11}$ D. R. McKenzie, Y. Yin, N. A. Marks, C. A. Davis, E. Kravtchinskaia, B. A. Pailthorpe, and G. A. J. Amaratunga, J. Non-Cryst. Solids 164, 1101 (1993).

${ }^{12}$ V. S. Veerasamy, G. A. J. Amaratunga, C. A. Davis, W. I. Milne, P. Hewitt, and M. Weiler, Solid-State Electron. 37, 319 (1993).

${ }^{13}$ V. S. Veerasamy et al., J. Phys. Condens Matter 5, L169 (1993). 
${ }^{14}$ V. S. Veerasamy, J. Yuan, G. Amaratunga, W. I. Milne, K. W. R. Gilkes, M. Weiler, and L. M. Brown, Phys. Rev. B 48, 17954 (1993).

${ }^{15}$ C. A. Davis, D. R. McKenzie, Y. Yin, E. Kravtchinskaia, G. A. J. Amaratunga, and V. S. Veerasamy, Philos. Mag. B 69, 1133 (1994).

${ }^{16}$ M. Weiler, S. Sattel, T. Giessen, K. Jung, H. Ehrhardt, V. S. Veerasamy, and J. Robertson, Phys. Rev. B 53, 1594 (1996).

${ }^{17}$ M. Weiler, S. Sattel, H. Ehrhardt, and J. Robertson, Proceedings of the Electrochemical Society Conference, Reno, NV, (Unpublished).

${ }^{18}$ S. R. P. Silva, K. J. Clay, S. P. Speakman, and G. A. J. Amaratunga, Diam. Relat. Mater. 4, 977 (1995).

${ }^{19}$ S. R. P. Silva, J. Robertson, Rusli , G. A. J. Amaratunga, and J. Schwan, Philos. Mag. B 74, 369 (1996).

${ }^{20}$ S. R. P. Silva, and G. A. J. Amaratunga, Thin Solid Films 270, 194 (1995).

${ }^{21}$ N. Kumar, H. Schmidt, and C. Xie, Solid State Technol. 38, 71 (1995)

${ }^{22}$ W. Zhu, G. P. Kochanski, S. Jin, and L. Seibles, J. Appl. Phys. 78, 2707 (1995).

${ }^{23}$ G. A. J. Amaratunga and S. R. P. Silva, Appl. Phys. Lett. 68, 2529 (1996).

${ }^{24}$ J. Robertson and C. A. Davis, Diam. Relat. Mater. 4, 441 (1994).

${ }^{25}$ J. Robertson and E. P. O’Reilly, Phys. Rev. B 27, 3760 (1987).

${ }^{26}$ R. A. Street, Phys. Rev. Lett. 49, 1187 (1982).

${ }^{27}$ R. F. Egerton, Electron Energy Loss Spectroscopy in the Electron Microscope (Plenum, New York, 1986).

${ }^{28}$ N. W. Ashcroft and N. D. Mermin, Solid State Physics (Saunders College Publication, New York, 1976), Appendix K.

${ }^{29}$ A. S. Argon, V. Gupta, H. S. Landis, and J. A. Cronie, Mater. Sci. Eng. A 107, 41 (1989)
${ }^{30}$ D. C. Green, D. R. McKenzie, and P. B. Lukins, Mater. Sci. Forum 52, 53, 103 (1989).

${ }^{31}$ B. Dischler, Proc. European Mater. Res. Symp. 17, 18 (1987).

${ }^{32}$ S. R. P. Silva, G. A. J. Amaratunga, and C. P. Constantinou, J. Appl. Phys. 72, 1149 (1992).

${ }^{33}$ A. R. Merchant, D. G. McCulloch, D. R. McKenzie, Y. Yin, L. Hall, and E. G. Gerstner, J. Appl. Phys. 79, 6914 (1996).

${ }^{34}$ H. Kaufman, S. Metin, and D. D. Saperstein, Phys. Rev. B 39, 13053 (1989).

${ }^{35}$ M. A. Tamor and W. C. Vassell, J. Appl. Phys. 76, 3832 (1994); M. A. Tamor, W. C. Vassell, and K. P. Carduner, Appl. Phys. Lett. 58, 592 (1991).

${ }^{36}$ G. Mariotto, F. L. Freire, and C. A. Achete, Thin Solid Films 241, 255 (1994).

${ }^{37}$ D. F. Franceschini, C. A. Achete, and F. L. Freire, Appl. Phys. Lett. 60, 3229 (1992)

${ }^{38}$ J. C. Philips, Rev. Mod. Phys. 42, 107 (1970).

${ }^{39}$ D. J. Miller and D. R. McKenzie, Thin Solid Films 108, 257 (1983).

${ }^{40}$ R. Kleber, K. Jung, H. Ehrhardt, I. Muhling, K. Breuer, H. Metz, and F. Engelke, Thin Solid Films 205, 274 (1991).

${ }^{41}$ M. Hoinkis, E. D. Tober, R. L. White, and M. S. Crowder, Appl. Phys. Lett. 61, 2653 (1992).

${ }^{42}$ S. Schutte, S. Will, H. Mell, and W. Fuhs, Diam. Relat. Mater. 2, 1360 (1993).

${ }^{43}$ A. Sadki, Y. Bounoh, M. L. Theye, J. vonBardleben, J. Cernogora, and J. L. Fave, Diam. Relat. Mater. 5, 439 (1996).

${ }^{44}$ M. F. Thorpe, J. Non-Cryst. Solids 182, 135 (1995). 